\title{
FOREWORD
}

\section{The Problem of Perseveration}

\begin{abstract}
According to Allison, ${ }^{1}$ the term "perseveration" was used first by Neisser in 1894 as a label for the repetitive production of the same response to different commands. No doubt the phenomenon called "perseveration" was observed by clinicians much earlier than that date because it is a very frequently occurring behavior associated with neurological disorders of the brain. In fact, perseveration is such a pervasive and vexing problem that it has received much clinical and research attention for more than 100 years. Interestingly, however, despite this attention, the mechanisms responsible for perseveration have remained elusive. ${ }^{2}$ What is more certain, is that perseveration is not a unitary phenomenon but rather manifests itself in various forms and across all modalities of response output. Speech and language pathologists and other clinicians working with individuals who have experienced such neurological events as strokes and traumatic brain injury and such progressive neurological disorders as Parkinson's disease and forms of dementia are well aware of the common occurrence of perseveration in these populations. Furthermore, they are familiar with the ways perseveration can interfere with assessment and treatment procedures and, more importantly, functional activities.
\end{abstract}

Perseveration is, perhaps, one of the most interesting behaviors observed by clinicians and studied by investigators from various disciplines. In my own clinical practice I am continually amazed at the ways perseveration can manifest itself. For example, I recently saw an individual who had experienced a large left hemisphere stroke and displayed what might be labeled "pervasive" perseveration. He displayed the three primary forms of perseveration (stuck-in-set, continuous, and recurrent; for definitions see McNamara and Albert, ${ }^{3}$ in this issue), and these forms occurred on various tasks and modalities. He often pointed to the same (incorrect) items on an auditory comprehension test, whereas on writing tasks he repeated letters and words. In drawing, elements of one drawing would be carried over to other drawings. His speech output was highly perseverative with inappropriate recurrence of both words and phonemes. Not surprisingly, the neuropsychologist evaluating him found that the same problems contaminated his performance and resultant test scores. In such cases, it appears that perseveration is blocking what may be at least partially preserved underlying skills. Those of us who are therapists cannot help but think about and pursue ways to "unblock" performance potential by helping such patients control and even eliminate there perseverative behaviors. To begin to accomplish such a feat, however, we must understand what perseveration is all about, what causes it, and what factors can increase or decrease its occurrence. In other words, if we are to develop successful methods for treating perseveration, we must get a better "handle" on underlying mechanisms.

As a "seasoned" clinician and therapist, I have a great interest in the puzzling problem of perseveration. So, when Hugh Buckingham and Sarah Christman offered to serve as guest editors for an issue of Seminars in Speech and Language devoted solely to perseveration, I was delighted. I was familiar with the excellent work and writing of both of these individuals and have read all of Dr. Buckingham's publications on perseveration. I knew that they would know the best people to write articles for this issue and that they would make my job as an editor-in-chief relatively easy in many ways. 
That proved to be the case. Not only did Buckingham and Christman make sure that I received a well-edited group of articles in a timely manner, but also they provided me with an opportunity to learn a great deal more about perseveration through reading these "cutting edge" articles. I think that all readers will find them as informative and intellectually provocative as I did.

In closing, I must point out that this is the last issue of Seminars in Speech and Language for which I will serve as Co-Editor in Chief. I have had the pleasure of doing this job for 5 years, during which time 10 issues devoted to adult topics were published. It has been a pleasure working with Nan Bernstein Ratner and the people at Thieme Medical Publishers, especially the very competent and pleasant Production Editor, Xenia Golovchenko, whom I have never met but feel I know. Thank you Xenia, and all the Guest Editors and authors who helped bring the 10 issues to fruition. It has been a multifaceted learning experience for me and I look forward to reading future "Adult Focus" issues of SSL that will be in the very capable hands of Audrey Holland starting with the next issue.

\section{REFERENCES}

1. Allison RS. Perseveration as a sign of diffuse and focal brain damage. I. BMJ 1966;2:1027-1032

2. Hotz G, Helm-Estabrooks N. Perseveration. Part I: a review. Brain Inj 1995;9:151-159

3. McNamara P, Albert ML. Neuropharmacology of verbal perseveration. Semin Speech Lang 2004;25: 309-322

Nancy Helm-Estabrooks, Sc.D. Co-Editor in Chief ${ }^{1}$ 